\title{
Gallo language: distribution area, functional status' dynamics and vitality factors
}

\author{
A.S. Bukhonkina \\ Institute of Philology and Intercultural Communication \\ Volgograd State University \\ Volgograd, Russia \\ bukanna@volsu.ru
}

\author{
V.P. Sviridonova \\ Institute of Philology and Intercultural Communication \\ Volgograd State University \\ Volgograd, Russia \\ v.p.tim@mail.ru
}

\author{
A.V. Stramnoy \\ Department of Economy and Managements \\ Volgograd State Technical University \\ Volgograd, Russia \\ lecha1981@mail.ru
}

\begin{abstract}
This paper discusses the distribution area, the functional status and vitality factors of the Gallo language relating to the languages of the northern regions of France (langues d'oil), and classified by UNESCO among the languages on the verge of extinction. The sociolinguistic situation in Upper Brittany, where they speak Gallo, requires close attention: it is more complex than in Lower Brittany, as the territory of the spread of its indigenous language is a buffer zone between the continental romance habitat and Breton enclave in the west of the peninsula. If the Breton language as a historical language of Upper Brittany is well known in France and abroad, the Gallo language is little known. This due to the fact that the Breton language has been considered as the only true historical language of Brittany. The paper analyses the dynamics of the functional status of the Gallo because the interest in its study has really increased, its positions have strengthened, as well as the overall social and cultural context related to regional languages in France has changed. In addition, the paper involves the analysis of the Gallo language generation transmission, actual number of the Gallo language speakers, spheres of its use and the degree of its vitality in conditions of domination of the majority (the French) language and the other local language (the Breton language).
\end{abstract}

Keywords-Gallo language; Upper Brittany; language vitality;

\section{INTRODUCTION}

The Breton language as a historical language of Upper Brittany is quite well known within and outside of France, whereas the language of Lower Brittany (Gallo) is little known and overshadowed by the former. This is due to several reasons. Firstly, for a long time Gallo had been wrongly perceived as a distorted local variant of the standard French language. This perception was connected to the fact that both Gallo and French are related to the language group that originated from the Northern Romance speech, which includes poitevin, norman and picardian dialects. As a result of a favourable historical and political context, French, among other equal languages, received the status of supradialectal language, acquiring such characteristics as writing and institutionality. The rest of the Northern Romance dialects gradually started to fade away and eventually either disappeared completely, preserved its rudiments in regional dialects, or, as in the case of Gallo, began to be perceived as dialectal variants of the French language. However, it is worth mentioning that Gallo is the only form of the Northern Romance speech that received the status of the regional language, which is acknowledged by the Ministry of National Education of France.

Secondly, the Breton language being the basis of the Breton identity has always been considered the only true language of historical Brittany and outmatched Gallo with this region being positioned as a successor of Celtic culture tradition. Breton has always had the status of the language even if it was supplanted from the local communicative environment. According to H.Walter, "the Breton language, apparently being different from French, seems more Breton as Romance forms of speech in Upper Brittany poorly contribute to image creating of Breton, the non-romance region. In this regard, residents of Upper Brittany are not considered to be Bretons, unlike residents of Lower Brittany" [1].

\section{DISTRIBUTION ZONE OF GALLO}

The term Gallo is of Breton origin and means "foreign, alien". Initially, this word was used to refer to those who did not speak the Breton language. First written usage of this term dates back to XIV century. Since that time it was more widespread in linguistic environment; the adaptation by the native speakers was sporadic as they prefered to call it "patois, uncultivated speech" (patois, parler local). Currently, it is quite difficult to identify language facts of the Romance region area as the major part of the spoken language in this area fits into the inherent form of speech (Gallo) along with acquired standard French. Due to the fact that Gallo and French have a lot in common, indigenous population does not perceive this mixed form of speech as a regional language. 
This can be proved by the results of several polls conducted in Brittany, which show that the local population does not understand the expression "regional French language" [2]. The main problem facing specialists in northern French dialects, which are closely-related to French, is to define the borders and separate them from regional variants of the French language. For the majority of people, Gallo is still considered to be 'patois'. It is indeed difficult for a foreigner to hear people spontaneously speaking Gallo as this form of speech is used within families [3].

Ille-et-Vilaine, the western part of Morbihan, the western part of Côtes-d'Armor and the northern part of LoireAtlantique are traditionally considered to be a distribution zone of Gallo. Gallo is mainly spoken in rural areas and less common in cities. Residents of these areas understand the local idiom worse than their parents and grandparents. Young and middle-aged people have the least understanding of this language. Despite the significant decrease in the number of people understanding and speaking Gallo, recently the number of those who want to study it as a part of school or university programme has increased [4].

Moreover, the continuing social stigmatization of Gallo probably entails slight distortion of polls' results, as respondents, especially the young ones, can deliberately underestimate (hide?) their communicative competence. In particular, the tests conducted by ERELLIF linguistic laboratory of the University of Rennes 2 in partnership with the Gallo Teachers' Association show that there is an obvious difference between reported and real respondents' competences. They overestimate the ability to understand Gallo and underestimate the ability to speak it themselves [5]. If a family circle used to be a channel for passing on Gallo, a regional form of speech, from the older generation to the younger one, currently the situation has changed. Today young generation first gets acquainted with the regional language at school, whereas communication in Gallo within a family has decreased.

\section{LANGUAGE PRACTICE. NUMBER OF NATIVE SPEAKERS}

Identifying language phenomena, which are subject to analysis, is extremely complicated in the zone of the Northern Romance speech (oil zone) because the language practice and native speakers' perception of it represent a sort of language continuum with two extreme points - local inherited idiom (Gallo) and the standard French language.

Between those two points, there are several other language phenomena (regionalized form of speech, form of speech that unites Gallo and the regionalized form of speech, so called les pratiques gallesentes, Gallo dialects.) Taking into account typological closeness and a high level of interference, transition from one part of this "language puzzle" to another is unnoticeable and that implies smooth differentiation of language facts, the absence of distinct boundaries between them. F. Manzano writes the following about this situation:

"Continuity of the transition from pole A to pole B, i.e. from French to Gallo, insures preservation of local dialects; $<\ldots>$ it is necessary to distinguish between Gallo and mixed form of speech that include Gallo (les pratiques gallesentes) as it is relatively easy to distinguish and classify French form of speech in this area. But it is incredibly difficult to say where Gallo begins if it really begins somewhere [6].

As a result, conducting polls about the transmission and use of this idiom in everyday life is complicated. Standard question for this analysis "How often and in what situation do you use the regional language?" does not require additional comments in the distribution zone of the Breton language, but it can be misunderstood by native speakers of Gallo, as they cannot identify it (which is possibly wrong) as a "language". Depending on social and age categories, informers can identify this form of speech as "Gallo", "regional language", "uncultivated speech", "patois". In this regard, those few polls conducted in Upper Brittany [CREDILIF, INSEE] avoid any categorization and designation of local idioms using such terms as "Gallo", "local idiom", "regional language" and "patois" as equavalents and choosing the same designation as an informer does.

The first complex poll, showing the number of Gallo speakers, was conducted in 1999 as a part of the project called «Étude de l'histoire familiale» (Study of family history) initiated by the National Institute of Statistics and Economic Studies (INSEE). According to its results, the number of Gallo speakers in historical Brittany was estimated to be 28 000 or $1 \%$ of its population, thus at that time Gallo took the 4th place in the region after French, Breton (11.3\%) and English (4.3\%) [7].

However, the results of this poll could give inexact information about the number of native speakers, as formal categorization of Gallo was not given in the questionnaire. The question "What regional language do you practice?" sounds incorrectly in Upper Brittany. Even those people who use Gallo in everyday life could give negative response to this question because they use different designation for this language phenomenon and call it patois, dialect, regional French and local speech. The modality of the questions can significantly influence respondents and distort the real sociolinguistic situation. In this case, "formal characteristics of the questionnaire determine understatement of Gallo speech practice and do not take into account all types of language transmission" [8].

The number of people speaking Gallo can significantly surpass the results of INSEE poll, not only because of the insufficiently elaborated categorical device but also because of the fact that "the majority of people speaking Gallo today do not identify their speech and presume that this language has no future. This makes it difficult to support this language. The closeness of French and Gallo language systems drags the latter into the linguistic orbit of the French language. On the one hand, it can be regarded as an advantage because learning Gallo seems easier than learning Breton. On the other hand, its closeness to French puts in question the usefulness of its learning" [9].

In 2005, research center CREDILIF in the University of Rennes 2 conducted a multiaspectual poll of Upper Brittany residents in order to determine the number of native speakers, conditions for transmission, geographical distribution, ratio of people who speak and understand the language, attitude to the 
language and other crucial characteristics. According to its results, the number of people speaking Gallo was $5 \%$ (versus $1 \%$ according to INSEE poll) of the historical Brittany's total population.

Analysis of typological, utilitarian, glottogonic, psycholinguistic and pragmatic questions of Gallo's functioning gave a good insight into this idiom [10].

The poll confirmed the general tendency of decreasing number of those who speak and understand Gallo. In particular, respondents of all age groups claimed that they understand Gallo less than their parents (12-26\%) and grandparents $(12-28 \%)$. People aged from 13 to 24 had the lowest percent $(18 \%)$ and the major part of people claiming to understand Gallo are young people who study it at school (68\%). Out of all respondents, only 5\% think that their children can speak Gallo but do it rarely; $8 \%$ say the same about their parents and $20 \%$ say it about older generations. Thus, there is noticeable generation regress of passing on the local idiom; the number of representatives of different generations who can speak and understand Gallo is decreasing.

The questions about understanding and using Gallo in everyday life were supplemented by texts in order to find out active (can speak, translate from French to Gallo), and passive (can understand, recognize speech in Gallo) language competences. Consequently, obvious differences between reported and real respondents' competences were found: they were prone to overestimate their ability to understand expressions in Gallo and underestimate their ability to transform the expressions into French.

According to the survey organizers, understatement and probably even hiding of Gallo linguistic competences, both productive and receptive, are connected to its long-term social discrimination. Nevertheless, according to CREDILIF laboratory the number of people speaking gallo equals 200,000 in absolute figures [11]. In 2013, TOM régions company, specialising in sociological research, in partnership with association "Cultural diversity of Brittany" conducted a survey among the residents of the region. The aim of the survey was to track the evolution of Brittany's sociolinguistic context including its linguistic heritage. 5\% of the respondents gave a positive response to the question "do you speak Gallo (patois)?" and 8\% claimed to understand the language [12].

\section{THE CONTEXT OF ASSIGNMENT OF LOCAL IDIOM/GALLO}

In majority of cases, people of older generations (65+) learned the inherited language (Gallo) within a family, i.e. in an implicit way, which implies the absence of conscientious efforts from an individual. In native speakers' conscious, the "maternal" character of the language learning is closely connected to affective speech context - "home, family, communication with relatives".

One of the respondents of the CREDILIF survey, a 70year-old woman, associates her Gallo speech practice with a specific emotional communicative locus: "avec ma grandmère quand on allait dans les champs ramasser des glands et des châtaignes / with my grandmother when we went to the fields to pick up acorns and chestnuts".
Walter points out that the Gallo language like others regional languages has changed in its functional role in French society, becoming a way for people to assert their identity. Walter observes that there is a mixture of loyalty at the emotional level to the languages of past "and an immoderate respect towards the French language". This, she says, has built up a contrasting linguistic landscape in France which looks all the more surprising today because, in spite of the gradual and fatal dwindling away of regional languages' since the beginning of the twentieth century, there is "a renewed and vivid interest on the part of the young in the words of their grandparents and the way they spoke." [13]

\section{STATUS OF GALLO: OFFICIAL RECOGNITION AND PERCEPTION DYNAMICS}

For a long time, the majority of people considered using Gallo, especially at school, to be a speech mistake and that is confirmed by the expression "se remettre à parler gallo" (resume speaking gallo), which has a meaning "to make a mistake". Vitality of this language can be partly explained by the fact that the native speakers perceived it as a local variant of French that was understood by francophones to some extent. As G.Walter points out, "the attitude to Gallo is ambivalent. On the one hand, people are ashamed of it and perceive it a speech flaw. On the other hand, people are very attached to it as to a traditional way of communicating within a family" [14]. For the most part, Gallo remains to be the language used in rural areas. Moreover, representatives of different age categories who live both in cities and in rural areas point out that Gallo is a language for "relatives", exclusively for a narrow circle of family members.

According to Blanchet and Walter, the term "Gallo" was, up to recent times, mainly used by intellectuals, linguists, teachers or activists whilst its adoption by speakers was still rare. Mainly due to its ever-increasing use in the media, the term is becoming gradually more employed today. When used by an outsider to Upper Brittany such as a person from Lower Brittany or a government representative, the negative connotation associated with patois becomes tangible for the Upper Breton [15].

As for a psychological aspect of using Gallo, nowadays there is no complex of language inferiority among young people. Over $50 \%$ of young people who study the language said that they do not have any particular feeling when they were asked "what do you feel when you speak Gallo?". Among other answers, there were also positive feelings of belonging to the region, its culture, historical heritage, etc.

The designation "Gallo" is primarily used by young people aged from 13 to 19 who study it at school, whereas middleaged and elder people call it patois. The difference in the choice of designation emphasises the difference of the idiom's perception by representatives of different generations. Perception of Gallo as of a language is not formed in the conscience of middle-aged and especially elder people who were brought up in ideologically charged linguistic policy, which devaluated regional languages. They can not ascribe the same status to this language as to French, Italian, Spanish and even Breton. Conscience of young people is free from the perceptions that divide language code into "worthy" and the 
rest. In this regard, designation of the local idiom as "Gallo" in contrast to "patois' or parler (local dialect) significantly contributes to its legitimation.

Apparently, the dynamics of the perception of Gallo by the native speakers and overestimating its status is determined by the changed government policy towards regional languages. One of the most significant and important steps on behalf on the regional authorities is acknowledgment of Gallo as "a language that belongs to linguistic heritage of France" in 2004 as, according to the constitution changed in 2008, all regional languages are included in the historical heritage.

Several years ago it became clear that in order for Gallo to acquire prestige and reputation, which this language deserves, it is necessary to create its own geographic system. In contrast to Provencal, Gallo has been a spoken language for centuries. There are several written texts in this language, but every author writes in his own way, trying to apply the principles of the French orthography to Gallo. Due to the absence of the codified orthographic standard, Gallo remains to be a spoken language. The functional volume that was initially attributed to Gallo as to a spoken language of communication within a family could be fully implemented without involving the written system. French is opposed to Gallo with its standard orthography and large-scale practice of written communication.

Despite the fact that some linguists, for example Jean-Paul Chauveau [16], made some attempts to document forms of spoken Gallo, writing in this language is still a task for specialists. Despite the appearance of different publications since the end of 80s (short stories, poetry collections, plays, translations of fables and comics), there are much fewer written texts in Gallo than, for example, in Breton. Attempts to narrow down different principles of written Gallo to the unified standard did not give anticipated results. It can be confirmed by understanding bilingual banners in French and Gallo in the Rennes Metro and could hardly be identified by the population due to the orthography which is different from French.

A significant advance in Gallo's political status in Brittany was its recognition in the Charte culturelle de la Bretagne in which it was described as a 'parler'. The charter was signed in 1978 by the Conseil régional de Bretagne, the French state and the departmental council of Loire-Atlantique and was the main cultural policy document, which delineated the local language policy in Brittany until 2004. In December 2004, 'Une politique linguistique pour la Bretagne' was adopted by the Conseil régional in which Gallo was described as a 'langue'. The inclusion of Gallo in the Charte culturelle was very influential in its adoption as an optional subject since 1982 and addition to the Baccalauréat school-leaving exam. It is still the only Oïl language variety that is examined at this level. It is a very considerable factor in the status policy ambitions of Gallo activists, considering the questions that surround Oïl varieties as languages in their own right.

\section{VITALITY FACTORS IN COMPARISON TO BRETON. TEACHING OF GALLO}

If the Breton language is compared to Gallo from the point of view of factors, contributing to its vitality and promotion in social spheres, then Breton is in a more favourable position. Secondly, the Breton language is perceived by the regional public as more "affected" and it means that it deserves preferential advantages and compensations for depriving several generations of Bretons of the possibility to know the language of their ancestors and to pass it on to future generations.

Secondly, the Breton language being the basis of the Breton identity has always been considered as the only true language of historical Brittany and outmatched Gallo with this region positioned as a successor of Celtic culture tradition. Breton has always had the status of language, even if it was supplanted from the local communicative environment.

A weaker position of Gallo in sociolinguistic Breton hierarchy shows itself in high attention to the Breton language on the part of regional authorities and the bigger number of education programmes in Breton, the amount of TV and radio broadcasts, printed publication and literature, unequal representation of Breton and Gallo on the Internet, etc.

According to several researchers [17], Breton and Gallo do not possess the same status connected to the function performed by them. The languages of Brittany are more than just the ways of communication. They are also vectors of identity and cultural symbols; that is why these two languages do not have the same significance and are not the same in collective consciousness [18].

The advantage of Breton over Gallo becomes obvious after analysing city and road landscape of Brittany. During the last decade, one of the most important aspects of regional policy is improvement of Brittany's image and its positioning as one of the most unusual French regions in order to enhance its attractiveness to investors and tourists. Sociolinguistic peculiarities of Brittany - its celtic roots and two minority languages that are related to different language groups proved to be very useful. Bilingual banners and direction signs perform not only a practical but also symbolical function and show linguistic diversity of the region.

The Gallo language has been a constituent of the educational system of Brittany for the last 30 years. Since 1982, students have enjoyed the opportunity to prove their knowledge of Gallo by passing a so-called baccalaureate exam (Le gallo au baccalauréat) upon graduation from a secondary school in some cities of the region. However, the Gallo exam is oral while those aimed at proving your knowledge of other regional languages (Breton, Basque, Flemish, Alsatian, Corsican and Occitan) also have a written version. Nowadays, the Gallo language is taught as an optional subject in 7 colleges and 9 lycées of the educational district of Rennes (académie de Rennes) as well as in the University Institutes for Teacher's Training (les I.U.F.M) in the cities of SaintBrieu and Vannes. More than 700 teenagers in colleges and lycées now study Gallo and over 2000 kids are taught the Gallo basics in private and public junior schools. Since 1991, 
lycée students had the opportunity to study Gallo remotely within linguistic programmes offered by the National Centre for Distance Education (CNED). However, these programmes were shut down in 2001 due to lack of students.

As for teaching Gallo in high school, the first Gallo course was introduced to the students of the University of Rennes 2 (l'Université Rennes 2). Despite the fact that Gallo classes were eliminated in 2002 due to lack of students, the Philological Department of the university and the CREDILIF (Centre de Recherche sur la Diversité Linguistique de la Francophonie) have been actively working to revive the teaching of Gallo. In the University of Nantes, Gallo is taught as part of teacher training. It is difficult to teach Gallo because this Romance language has no unified writing system and as an idiom, it is mostly spoken and not written. Gallo teachers inevitably end up dealing with an issue of moving from oral transmission of the language to its teaching as strictly provided for by school and university programmes.

It is also possible to study Breton and Gallo beyond school. Since 1948, there have been KEAV summer courses of the Breton language for teenagers in the Cornouaille region. The U.B.A.P.A.R association (Union Breton pour l'animation des pays ruraux) offers students various leisure activities in Breton and Gallo during summer holidays.

According to the latest data, Gallo is regularly spoken and understood by 200000 to 400000 and 400000 to 800000 of Bretons respectively [Chevalier, 2008, p. 82]. The has been a considerable increase in the popularity of Gallo over the last three decades. France's Ministry of National Education acknowledged Gallo as one of the minority languages. Dozens of Gallo supporting associations and movements were created. It began to be taught in secondary and high school and used on radio and television.

Over the last decades, a number of organisations aimed at promoting Gallo and the traditional culture were founded in the region due to linguistic ecology issues becoming more pressing. The Brittany Cultural Charter made it possible for Gallo to be included in the programme of the University of Rennes (the compulsory Gallo Language and Culture course was introduced). Since 1982, the National Education Centre has been offering Gallo courses and since 1983, students have had the opportunity to pass a graduate exam. One also has to pass entry exams to be admitted to a pedagogical institute or enter civil service. Gallo is studied in pedagogical institutes of Rennes and Vannes and as part of professional training all over Upper Brittany.

\section{CONCLUSION}

The sociolinguistic situation in Upper Brittany is more complicated than in Lower Brittany as the distribution area of its indigenous language is a buffer zone between continental Romance area and Breton enclave on the west of peninsula. The influence of the Breton substrate, as well as French superstrat, characterizes Gallo. From the historical point of view, French and Gallo are equal as both of them originate from Vulgar Latin and relate to Northern dialects of Romance speech, but at the same time, sociolinguistic positions of francien dialect (which eventually became French) are much more powerful.

French was early distinguished from the dialects called langues d'oïl as an intermediary language for communication between different ethnic groups, and it was quickly established in written form. The rigid and planned policy, which started right after bourgeois revolution, was intended to spread and establish French as an official language, as well as to discard local languages and dialects. This policy continued and intensified after introduction of compulsory school education. One of the results followed by this policy was acknowledgment of all Northern Romance languages including Gallo as dialectal variants of French and even "a distortion" of French, and it is sometimes unified with the term that has a pejorative connotation - "patois" (uncultivated speech). Coexistence of Gallo and French for 200 years entailed interfusion of two forms of Romance speech and today it is possible to hear Gallo with lots of French borrowings and vice versa.

The sociolinguistic situation in Brittany is characterized by mutual influence of Breton, Gallo and French. With obvious predominance of French in all social spheres, native speakers of Breton and Gallo aspire to transmission of their languages from one generation to another and that is why Brittany can again be called a region with three languages. At the same time, French in Brittany is different from the standard French language as its vocabulary has many Gallo and Breton borrowings. Some of the word-formation models are also borrowed from these languages, which confirms its status of a regional variant of the French language.

\section{References}

[1] H. Walter, Adventures and misfortunes of the languages of France. Paris: Champion classics, 2012, p. 177.

[2] Ph. Blanchet and H. Walter, Dictionary of regional French of High Brittany. Paris: Bonneton, 1999, p.3.

[3] Ch. Leray, "The alternation of languages in High - Brittany," in Sociolinguistics Books, vol. 7, Paris: L'Harmattan, pp. 123-132, 2002.

[4] Ph. Blanchet and A. Le Coq Jahier, "Where is the gallo? Practices and representations of language and of culture in High Brittany," in Sociolinguistics Books, vol. 12, Paris: L'Harmattan, pp. 11-29.

[5] J.-P. Angoujard, and F. Manzano, "Around gallo: analyses and perspectives," in Sociolinguistics Books, vol. 12, Paris: L'Harmattan, pp. 5-10, 2007.

[6] F. Manzano, "Diglossie, contacts and conflicts of languages... In the test of three géo-linguistic domains: High Brittany, occitano-Romance South, the Maghreb," in Sociolinguistics Books, vol. 12, Paris: L'Harmattan, pp. 51-66, 2003.

[7] I. Le Boëtté, "Breton language and other languages: practice and transmission," in Octant, No. 92, Insee Bretagne, pp. 18-22, 2003.

[8] Ph. Blanchet, L.-J. Calvet, D. Hillereau, and E. Wilczyck "The linguistic stage of the French inventory of 1999. Results and analysis applied in multilingual Provence," in Linguistic Margins, No. 10, Paris: M.L.M.S, pp.23, 2005.

[9] R. Le Squere, An analysis sociolinguistique marking of the territory in Brittany: toponymy, bilingual display, cultural identites and developpement regional. Rennes:Linguistics. Rennes University, 2007, p. 123. 
[10] Ph. Blanchet and A. Le Coq Jahier, "Where is the gallo? Practices and representations of language and of culture in High Brittany," in Sociolinguistics Books, vol. 12. Paris: L'Harmattan, pp. 11-29, 2007.

[11] G. Chevalier, "Gallo and Breton, complementarity or competition?," Sociolinguistics Books, vol. 12, Paris: L'Harmattan, pp. 75-109, 2007.

[12] http://bcd.bzh/fr/les-resultats-du-sondage-bcd-en-ligne/

[13] J. Nolan, "Reassessing Gallo as a regional language in France: language emancipation vs. monolingual language ideology", in International Journal of the Sociology of Language, vol 6, De Gruyter, pp. 91-112, 2011.

[14] H. Walter, The French in all directions. Paris:Robert Laffont, 1998, p.187.
[15] J.S. Nolan, "Reassissing Gallo as a regional language in France: language emancipation vs. monolingual language", in International Journal of the Sociology of Language, vol 6, De Gruyter Open, pp. 1-23, 2011

[16] J.-P. Chauveau, Phonetic evolutions in gallo. Paris: CNRS, 1998, p. 76.

[17] T. Bulot, "The discursive production of norms: sociolinguistique centralisation and multipolarization of reference areas," in French Language Studies, vol 16 / 3. Cambridge: Cambridge University Press, pp. 305-333, 2006.

[18] R. Le Squere, D. Ar Rouz, "Translation and public display: what service (s) for the regional languages of Brittany?," in Linguistic Margins, No. 10. Paris: MLMS, 2005, p.17. 